\title{
Characteristics of Large-Scale Harmful Algal Blooms (HABs) in the Yangtze River Estuary and the Adjacent East China Sea (ECS) from 2000 to 2010
}

\author{
Li Shen ${ }^{1 *}$, Huiping $\mathrm{Xu}^{1}$, Xulin $\mathrm{Guo}^{2}$, Meng $\mathrm{Li}^{2}$
}

\footnotetext{
${ }^{1}$ State Key Laboratory of Marine Geology, Tongji University, Shanghai, China; ${ }^{2}$ Department of Geography and Planning, University of Saskatchewan, Saskatoon, Canada.

E-mail: *shenli0630426@gmail.com
}

Received September $9^{\text {th }}, 2011$; revised October $12^{\text {th }}, 2011$; accepted November $17^{\text {th }}, 2011$.

\begin{abstract}
Harmful algal blooms (HABs) are a serious worldwide issue which has posed great risks on marine ecosystems and public health by directly releasing toxins or indirectly leading to anoxia in marine environment. In recent years HABs have caused huge economic losses in China, particularly in the Yangtze Estuary and the adjacent East China Sea (ECS). The present study investigated the spatial-temporal and species characteristics of large-scale HABs in this area using geographic information system (GIS) Kernel Density Estimation (KDE) spatial analysis, statistical methods and satellite image interpretation. Results revealed that the Yangtze Estuary, Zhoushan island, Xiangshan bay and Jiushan island are the regions with highest frequency of large-scale HABs. HABs in the ECS reached a peak in terms of total number and area in 2003 to 2005 and occupied a high percentage (around 70\% in area and 60\% in occurrence) in the four Chinese coastal waters. The number of large-scale $H A B s\left(>1000 \mathrm{~km}^{2}\right)$ in the Yangtze Estuary and the adjacent ECS declined after 2005 while that of HABs $\left(>100 \mathrm{~km}^{2}\right)$ declined after 2008. Large-scale HABs occurrences concentrated in summer (May to July), and the averaged duration increased continually from the shortest time (1.3 days) in 2001 to the longest (10.9 days) in 2010 for each HAB. 17 causative species were found with Prorocentrum dentutam as the most frequent dominant species, followed by Skeletonema costatum, Karenia mikimotoi, and Chaetoceros curvisetus. Water discoloration observed in MODIS satellite true color images was well consistent with the corresponding HABs reported by State Oceanic Administration of China (SOA). Multiple factors involving eutrophication, physical dynamics, topography and deposition conditions contributed to the formation of frequent HABs in the ECS. Three strategies including establishing a synthesized system, improving the previous database and investigating multiple contributors were proposed for future HABs monitoring and management.
\end{abstract}

Keywords: Harmful Algal Blooms (HABs), Yangtze Estuary, The East China Sea, Spatial and Temporal Characteristics, Causative Species, Remote Sensing

\section{Introduction}

Harmful algal blooms (HABs), also known as "red tides", have become a serious environmental issue which draws great attention in both governments and academic communities worldwide. Especially in recent years most coastal areas around the world are severely suffering from HABs of increasing frequency and expanding spatial extent $[1,2]$. HAB phytoplankton species can cause damage to marine ecosystems as well as public health in two ways. One is to directly release toxins and the other is to induce hypoxia and anoxia of marine organisms by accumulating biomass $[3,4]$. HABs are considered as one of the biggest marine disasters due to the considerable environmental contamination and huge economic losses as a result of mass morality of aquaculture [5,6].

China is a country with board coastal areas contributed by four marginal seas namely Bohai, Yellow Sea, the East China Sea (ECS) and the South China Sea, have been post great risk by HABs every year since the first documented HAB in 1933 [2,7]. According to previous investigation, the ECS, consisting of broad waters (the Yangtze Estuary, 
the coastal areas of Zhejiang and Fujian province), is the area most rigorously impacted by HABs among the four main coastal waters nationwide. In particular, the Yangtze River and the coast of Zhejiang Province are the hotspots of frequent large-scale and intensive HABs in the ECS [7-9]. Economic developments facilitated by aquaculture industries and coastal recreations of Shanghai (the number one metropolis in China) and Zhejiang Province (the most developed region in China) are threatened by annual HAB occurrences in the aforementioned areas. Worse still, Chen et al. [10] pointed out that those HABs in the ECS if last for more than 3 weeks might be transported to the Japanese or Korean coast by Kuroshio to cause worldwide harm. Therefore, studying the HABs trends in the ECS with regards to the spatial-temporal characteristics is of great significance for forecasting marine damage, protecting public health as well as promoting economic development not only in China but also in other neighboring countries.

In the present study we analyzed the spatial and temporal variability of historical large-scale HAB events from 2000 to 2010 in the Yangtze Estuary and the adjacent ECS water using GIS techniques and statistical methods. We also used MODIS satellite data to show the potentiality of observing large-scale HABs in the true com- posite imagery derived from basic remote sensing processing and interpretation. In addition, the contributing factors for frequent HABs and potential strategies for monitor ring such HABs are also discussed.

\section{Materials and Methods}

\subsection{Study Area}

Our study area is the ECS specifically in the Yangtze River Estuary and the adjacent water (around $27^{\circ}-32^{\circ} \mathrm{N}$, $120^{\circ}-123^{\circ} \mathrm{E}$ ) shown in Figure 1. As a marginal sea, the ECS lying between the Asia Continent and the Pacific Ocean, has broad water with a variety of islands (Huaniao shan, Ma'an, Shengsi, Zhoushan, Jiushan, Yushan, Dong ji, Dongtou and Nanlu). The complicated oceanographic characteristics in this region are contributed by the interaction of complex circulation systems, meteorological conditions as well as geological topography. This area is also characterized by high entrophication and primary productivity from various nutrition sources such as the runoff of the Yangtze River and the coastal subsurface water [11]. This area with the largest fishery in Zhoushan and Shengsi islands plays an important role in the local and national economical growth but at the same time suffers from serious HABs every year. Locations of

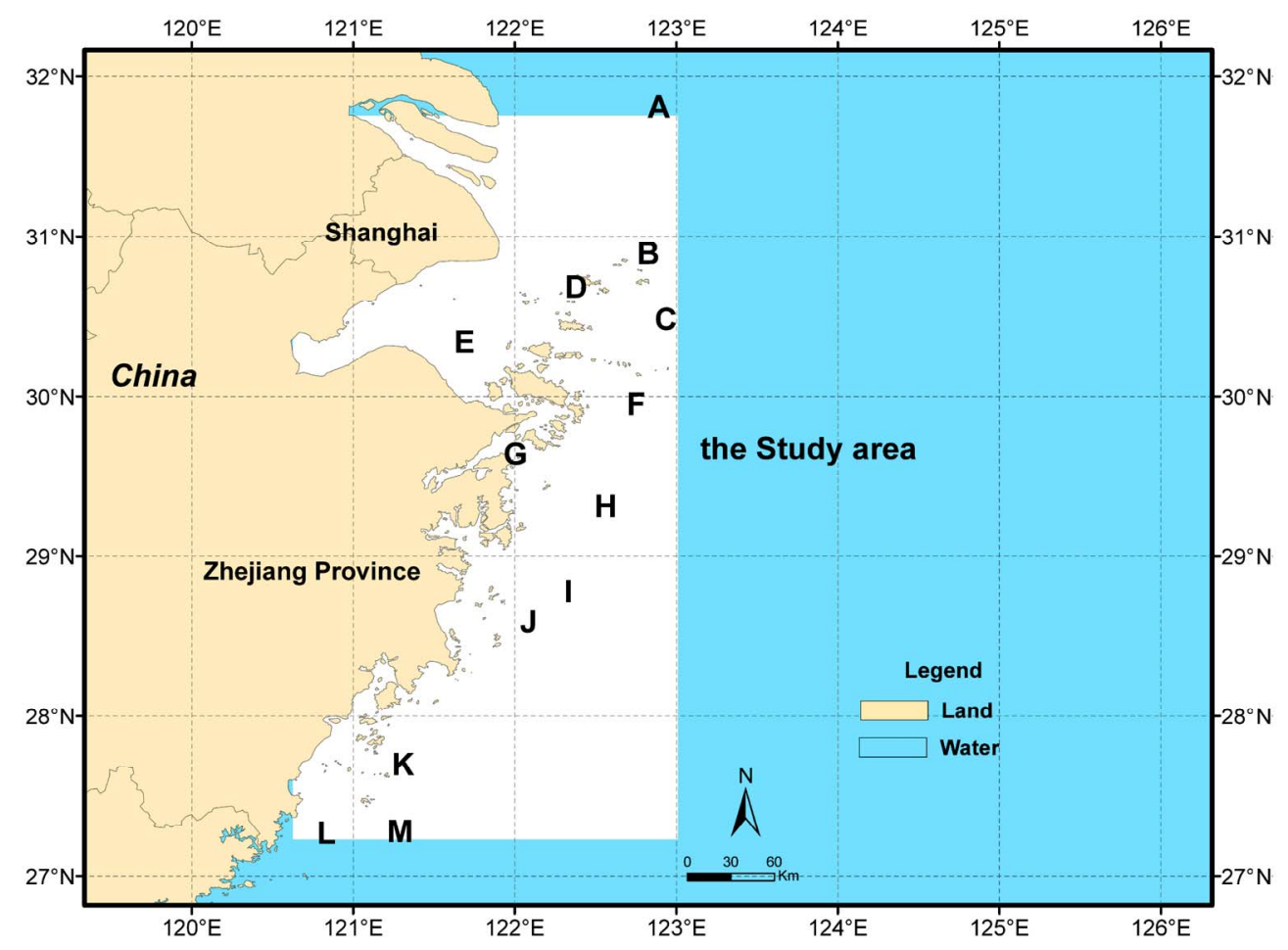

Figure 1. The study area and locations of historical frequent HABs (alphabetically marked). A. (the Yangtze Estuary), B. (Huaniao shan island), C. (Ma'an island), D. (Shengsi island), E. (Hangzhou bay), F. (Zhoushan island), G. (Xiangshan bay), H. (Jiushan island), I. (Yushan island), J. (Yushan island), K. (Dongtou island), L. (Cangnan areas), and M. (Nanlu island). 
historical frequent HABs are alphabetically marked in Figure 1.

\subsection{Data}

We have collected a total of 84 large-scale HABs events (coverage $>100 \mathrm{~km}^{2}$ ) in the study area for the past 11 years (2000-2010) from annually reported bulletins including the China Marine Environmental Quality Bulletin, the China Marine Disasters Bulletin and the Shanghai Marine Environmental Quality Bulletin by the State Oceanic Administration of China (SOA) [12-14]. Those data was obtained from the HAB database established by previous research projects conducted in the $11 \mathrm{HAB}$ monitoring stations which were set up in the ECS by the SOA [7]. More detail information including the start-end time, locations, areas, causative species, as well as cell concentrations of each $\mathrm{HAB}$ event can be provided through ship-tracking surveys, autonomous moorings and volunteer's investigation [15].

Moderate Resolution Imaging Spectrometer (MODIS) L1B satellite data was used to demonstrate large-scale HABs at a broad spatial scope from space. MODIS is a remote sensor with 36 spectral bands $(0.405$ to14.385 $\mu \mathrm{m})$ at three spatial resolutions $(250 \mathrm{~m}, 500 \mathrm{~m}$, and $1000 \mathrm{~m})$, and it can view the entire earth surface every 1 or 2 days. The advantages in spectral, temporal and spatial resolutions of satellite imagery can lead to more efficiency in large-scale HABs monitoring. We obtained those data from NASA at LAADS Web (http://ladsweb.nascom. nasa.gov/).

\subsection{Spatial Analysis of HABs}

Geographical information system (GIS) spatial analyst method was applied to conduct the spatial pattern analysis for the eleven-year (2000 to 2010) large-scale HAB events $\left(>100 \mathrm{~km}^{2}\right)$ in the Yangtze Estuary and the adjacent ECS. ArcGIS (10.0 version) was the platform to perform the analysis. Overlaid on a basemap of the ECS, a new point shapefile layer was created to exhibit those HAB events with the relative information stored in an attribute table. Each HAB event was represented by a central point of the polygon shape of the actual HAB coverage. Wang and Wu [2] suggested using this point pattern due to the difficulty of measuring the exact irregular and variable shape of a HAB coverage. Besides, they also pointed out that GIS techniques have more advantages in point pattern analysis than in polygons. The geographic coordinate was determined according to the location information of each $\mathrm{HAB}$ event provided by the SOA. And the projection of these HAB points was assigned GSC-WGS-1984 consistent with the coordinate system of the basemap. The geographical boundary of the spatial analysis is set according to the extent of our study area.

The frequency of HAB occurrences can be obtained from the degree of point concentration on a continuous density surface created by Kernel Density Estimation (KDE). KDE is a spatial analysis method with a kernel defined by a circle in a certain radius moving across the study area. The distance from the centre of the circle to the $\mathrm{HAB}$ point is measured to give the weight for that $\mathrm{HAB}$ event and to determine the density for the centre point [16].

\subsection{Temporal Analysis of HABs}

We analyzed the total occurrence and area of HABs in the ESC in each year from 2000 to 2010 as well as its percentage of the summed $\mathrm{HAB}$ events among all the four Chinese coastal waters. In the Yangtze Estuary and the adjacent ECS water, we mainly focus on large-scale HABs with an area over $100 \mathrm{~km}^{2}$. The coverage variation of large-scale HABs at two levels $\left(>100 \mathrm{~km}^{2}\right.$ and $>1000$ $\mathrm{km}^{2}$ ) in our study area from 2000 to 2010 was investigated. We have also compared occurrences in three different periods (spring, summer, and autumn) to understand the seasonality pattern of large-scale HABs $(>100$ $\mathrm{km}^{2}$ ). In addition, the average duration for HABs (>100 $\mathrm{km}^{2}$ ) in each year was extracted from the time data of each $\mathrm{HAB}$ event. We also investigated the causative species of large-scale HABs $\left(>100 \mathrm{~km}^{2}\right)$ in the past 11 years and ranked them in terms of HAB occurrences and area.

\subsection{Detection of Satellite Imagery}

Water discoloration observed in the satellite imagery has great possibility in indicating large-scale $\mathrm{HAB}$ events and revealing their location and size information $[8,17]$. Here we selected 3 relatively cloud-free scenes of MODIS L1B data to demonstrate this application. The original data was preprocessed by implementing radiometric and geometric corrections to derive reflectance values. Then three spectral bands $645 \mathrm{~nm}$ (Red), $555 \mathrm{~nm}$ (Green) and $465 \mathrm{~nm}$ (Blue) were combined into one true color composite image which can reflect the real information of earth surface. Equalization enhancement method was used to improve the clearance of the images for better interpretation. Admittedly, not all HABs can be distinguished from neighboring water due to their inconspicuous anomaly; however, visual interpretation can still be an easy and necessary procedure to avoid missing any occurrence sign of HAB events.

\section{Results and Discussions}

\subsection{Spatial Characteristics of HABs}

Figure 2 shows the spatial distribution of large-scale 


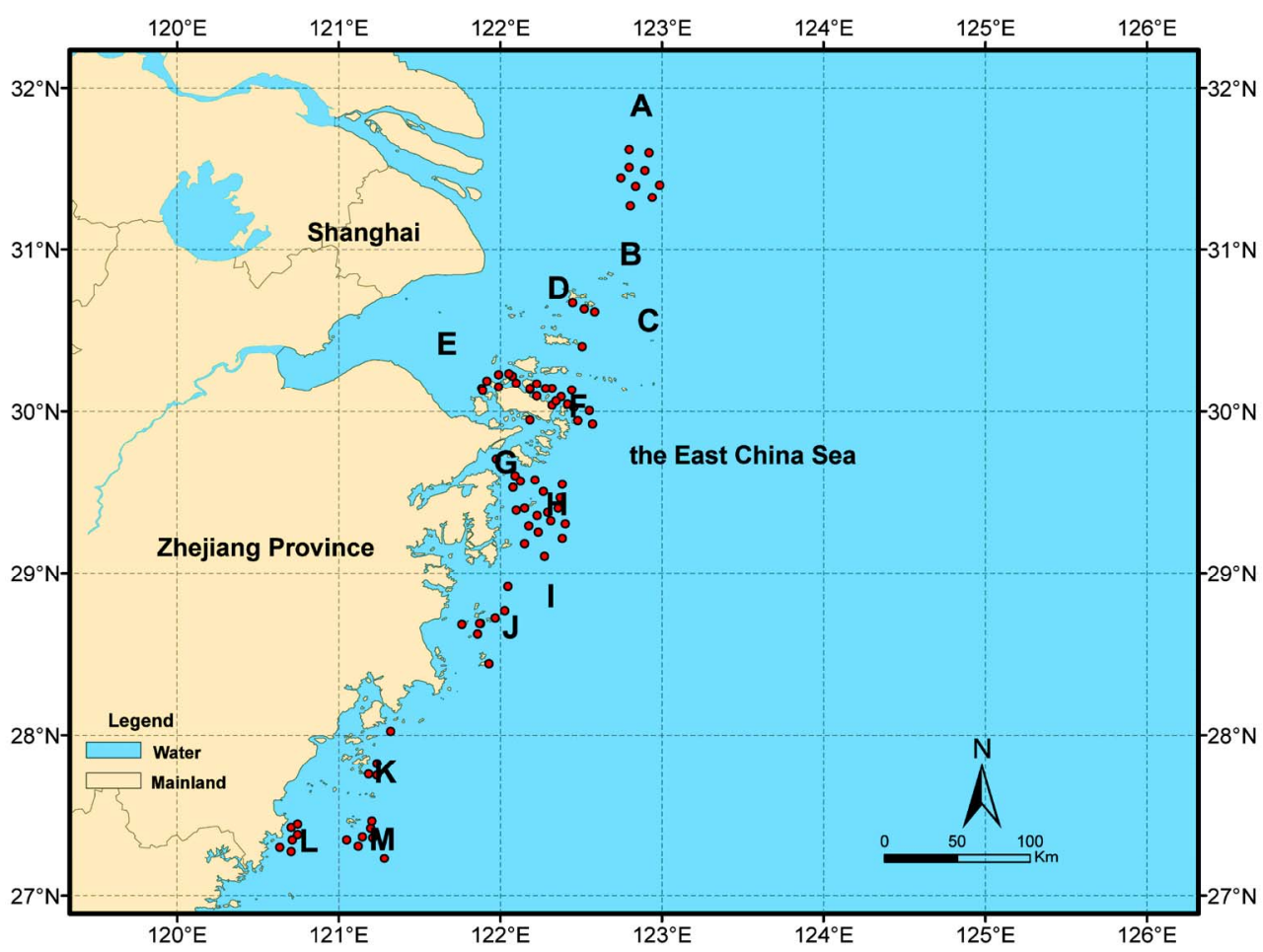

Figure 2. Locations of large-scale HABs $\left(>100 \mathrm{~km}^{2}\right)$ in periods from 2000 to 2010 in the Yangtze Estuary and the adjacent ECS water. Each point represents one HAB event.

HABs $\left(100 \mathrm{~km}^{2}\right)$ in the study area from 2000 to 2010. In general, they widely dispersed in all coastal waters of Shanghai municipality as well as Zhejiang province, and clustered in some certain areas. The KDE result (Figure 3) showed that the Yangtze Estuary (A), Zhoushan island $(F)$, Xiangshan bay $(\mathrm{G})$ and Jiushan island $(\mathrm{H})$ are the regions with highest frequency of large-scale HABs, and these regions are also hotspots of HABs at normal scales in the ECS along isobaths of $30-60 \mathrm{~m}$ in the ECS [2,7]. High frequency of large-scale HABs appeared in around $20 \mathrm{~km}$ scope outside of the HAB hotspots, and areas of medium frequency were observed in regions of another $20 \mathrm{~km}$ away. Other areas have comparatively low possibility to induce large-scale HABs

\subsection{Temporal Characteristics of HABs}

Both occurrences and areas of HABs in the ECS were found to be sharply increasing in the early years of the past 11 years from 2000 to 2010 until a peak appears (2003 for occurrences and 2005 for areas), and then showed a decreasing pattern in the rest years (Figure 4(a)). Particularly in 2004 and 2006, HAB occurrences and areas appeared contrast variation characteristics (low HAB occurrence with high bloom area), indicating that the scale of these HABs are large enough to cover a huge area in despite of a small number of occurrences. After 2006, the scale of HABs in the ECS became smaller which can be found in Figure 4(a). Figure 4(b) shows that HABs in the ECS accounted for a high percentage of the total HABs in the all four Chinese coastal water in terms of occurrence number and areas, especially in 2002 (64.6\% for occurrence and $88.7 \%$ for area), 2003 (72.3\% for occurrence and $89.3 \%$ for area) and 2008 (69.6\% for occurrence and $88 \%$ for area).

In the Yangtze Estuary and the adjacent ECS water, number of HABs with an area over $1000 \mathrm{~km}^{2}$ has an increasing trend from 2000 to 2005, but declined in the next half of these 11 years (blue histograms in Figure 5). In 2005 alone, the occurrences of such large-scale HABs were found to reach 8. Red histograms in Figure 5 illustrated occurrences of HABs over $100 \mathrm{~km}^{2}$ kept rising until 2008 with a peak of 16, and in the last two years decreased but still maintained at a higher lever (over 9).

We also investigated the seasonality and duration of large-scale HABs $\left(>100 \mathrm{~km}^{2}\right)$ in this area. The hotspot season of HABs was observed in Figure 6 to fall in summer (May-July) with an annually averaged occurrence of 6.27 , and a total number of 66 responsible for $78.4 \%$ of the documented $88 \mathrm{HABs}$ from 2000 to 2010. Prior to 2007, only one large-scale HAB $\left(>100 \mathrm{~km}^{2}\right)$ event was reported in autumn (August to October) but later than 200712 HABs $\left(>100 \mathrm{~km}^{2}\right)$ were recorded in autumn. In 


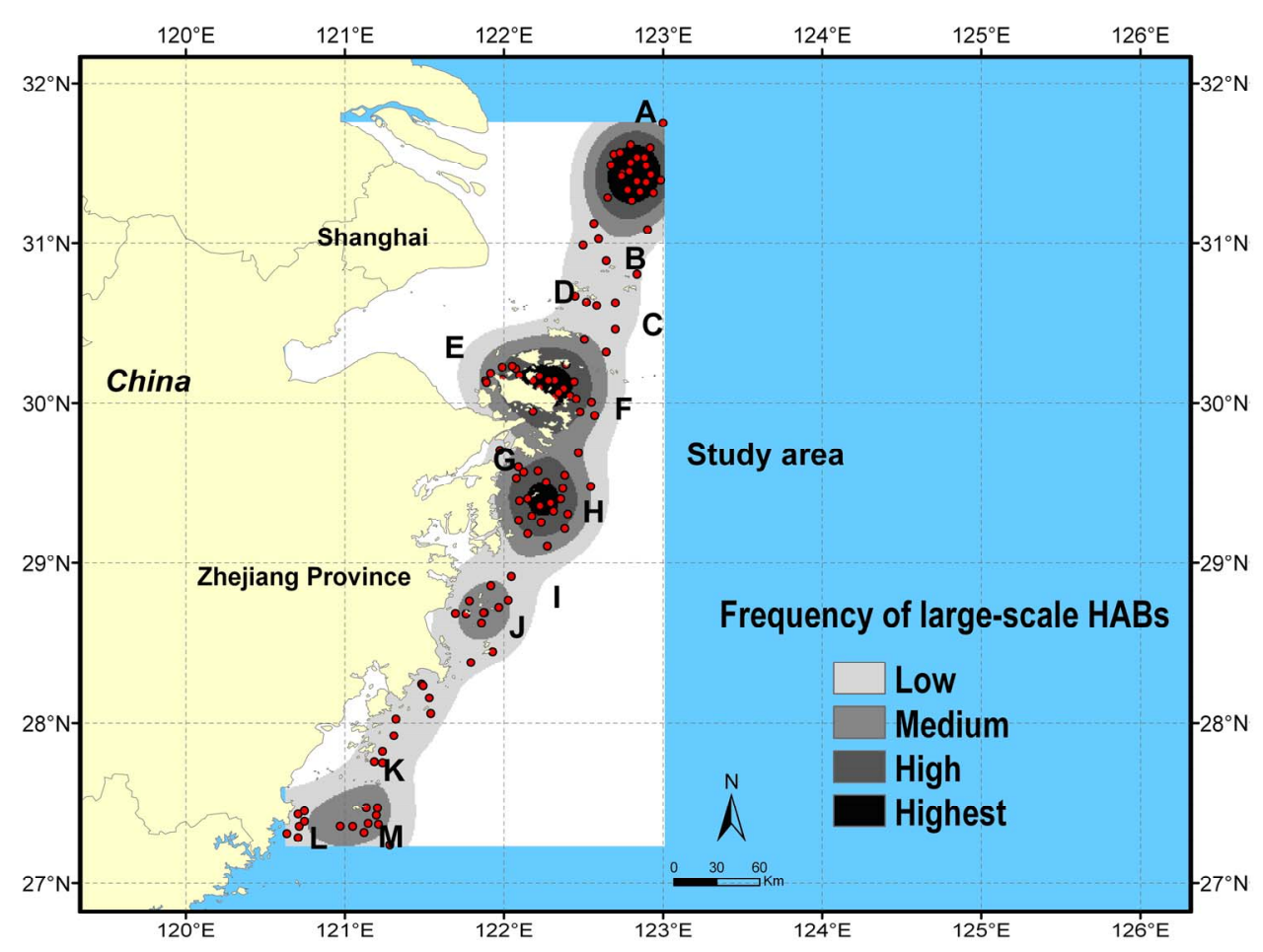

Figure 3. Kernel Density Estimation (KDE) result conducted by GIS spatial analyst for large-scale HABs frequency in the study area from 2000 to 2010. Four categories of HAB frequency were obtained.

spring (February to April) large-scale HABs were seldomly found with an annually averaged number of 0.45 (Figure 6). The averaged duration for large-scale HABs $\left(>100 \mathrm{~km}^{2}\right)$ are found to grow continually with a few slight fluctuation. The shortest time of a HAB was 1.3 days in 2001 and the longest achieved 10.9 days in 2010 (Figure 7).

\subsection{Variation of Causative Species}

17 causative species of large-scale HABs $\left(>100 \mathrm{~km}^{2}\right)$ inthe Yangtze Estuary and the adjacent ECS from 2000 to 2010 were listed in Table 1. Most species can be identified to known species while some were named at family or genus level. Prorocentrum dentutam was ranked number one dominant species occupying 42 events with a total area of 46,510 $\mathrm{km}^{2}$, followed by Skeletonema costatum dominating $29 \mathrm{HAB}$ events with an area of 23,110 $\mathrm{km}^{2}$, Karenia mikimotoi with 12 occurrences and 20,260 $\mathrm{km}^{2}$, and Chaetoceros curvisetus with 9 occurrences and $3600 \mathrm{~km}^{2}$. Among them, Karenia mikimotoi, a toxinreleasing species, was firstly found in 2004 in the ECS, and then caused more intensive HABs in later years [2]. Prorocentrum dentutam and Skeletonema costatum are non-toxin species but can accumulate biomass to cause hypoxia and anoxia of the marine environment. Chen et al. [10] concluded that Prorocentrum dentutam had taken the place of Skeletonema costatum to become the top one

Table 1. Table type styles (Table caption is indispensable).

\begin{tabular}{ccc}
\hline Causative Species & Occurrences & Areas $\left(\mathrm{km}^{2}\right)$ \\
\hline Prorocentrum dentutam & 42 & 46,510 \\
Skeletonema costatum & 20 & 23,110 \\
Karenia mikimotoi & 12 & 20,260 \\
Chaetoceros curvisetus & 9 & 3600 \\
Mesodinium rubrum & 4 & 1910 \\
Scrippsiella trochoidea & 4 & 3900 \\
Thalassiosira sp. & 3 & 8400 \\
Pseudo-nitizschia pungens & 3 & 800 \\
Ceratium fusus & 2 & 620 \\
Noctiluca scintillans & 2 & 1500 \\
Prorocentrum triestinum & 2 & 3400 \\
Gymnodinium sp. & 1 & 3000 \\
Microalgae & 1 & 100 \\
Gonyaulax spinifera & 1 & 300 \\
Chaetoceros compressus & 1 & 700 \\
Ceratium furca & 1 & 100 \\
Leptocylindrus danicus & 1 & 100 \\
\hline & & \\
\hline & & \\
\hline
\end{tabular}




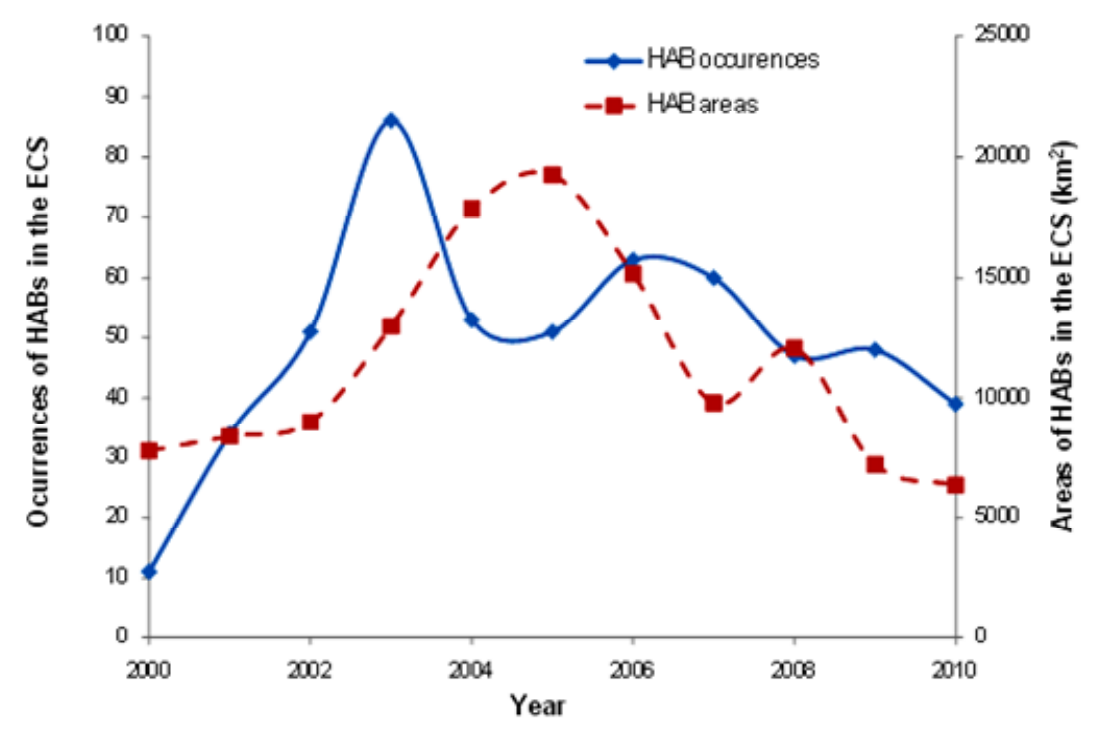

(a)

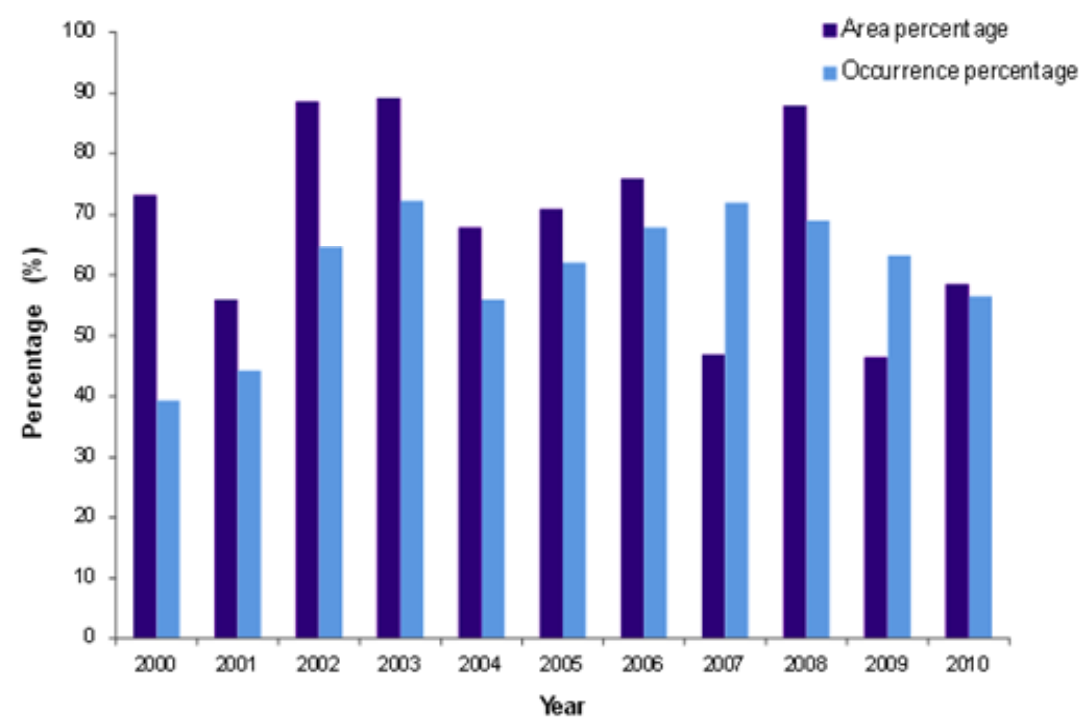

(b)

Figure 4. HAB occurrences and areas in the ECS from 2000 to 2010. (a) Total number and area of annual HABs. (b) Percentage of HABs (ECS) of the all four Chinese coastal areas.

HAB causative species in the ECS. One Prorocentrum dentutam HAB was observed covering an area over 10,000 $\mathrm{km}^{2}$ in 2004. Other phytoplankton species seldomly caused large-scale HABs by itself but in a seconddary role cooperating with the dominant species.

\subsection{Observation of HABs in Satellite}

MODIS true color composite images (Figure 8(a-c)) showed the water discoloration of two large-scale HABs in May to June, 2005. According to the recorded HAB information provided by the SOA, a HAB with the coverage of $7000 \mathrm{~km}^{2}$ caused by Prorocentrum dentutam and
Karenia mikimotoi occurred in the Yangtze Estuary from May 24, 2005 to June 1, 2005. In the same year, another large-scale HAB over $400 \mathrm{~km}^{2}$ caused by Skeletonema costatum was also found in the Yangtze Estuary with cell concentration of $4.2 \times 10^{7} / \mathrm{L}$ from June 15 , to June 21 [12-14]. The areas circled in a highlighted red box were the anomalies caused by the accumulated biomass of the HAB phytoplankton, in notable contrast with the neighboring waters. The locations of these discolored areas were confirmed by the distribution information of the corresponding HABs reported by the SOA. Those abnormal regions are well consistent with the areas of fre- 


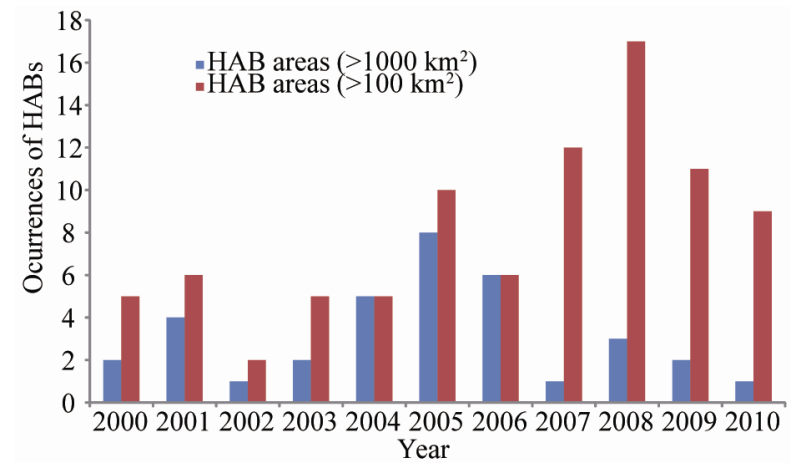

Figure 5. Occurrences of large-scale HABs at two levels (> $100 \mathrm{~km}^{2}$ and $>1000 \mathrm{~km}^{2}$ ) in the Yangtze Estuary and the adjacent ECS from 2000 to 2010.

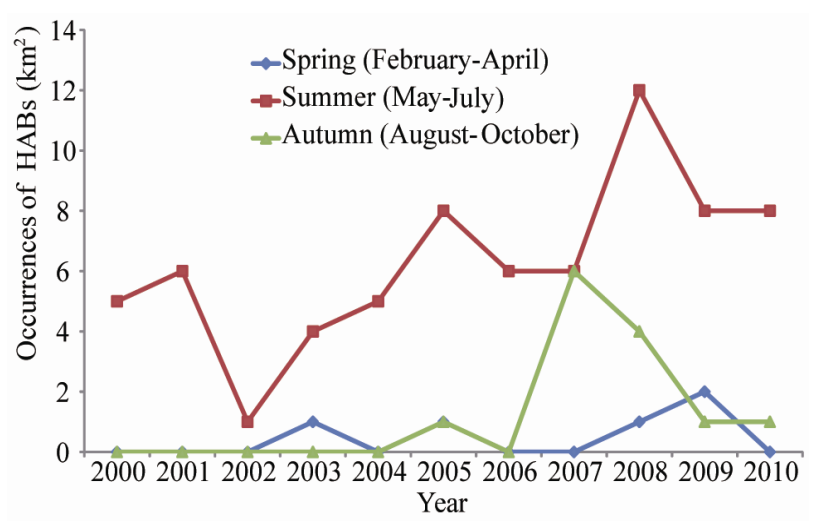

Figure 6. Seasonal occurrences of large-scale HABs $(>100$ $\mathbf{k m}^{2}$ ) in the Yangtze Estuary and the adjacent ECS from 2000 to 2010.

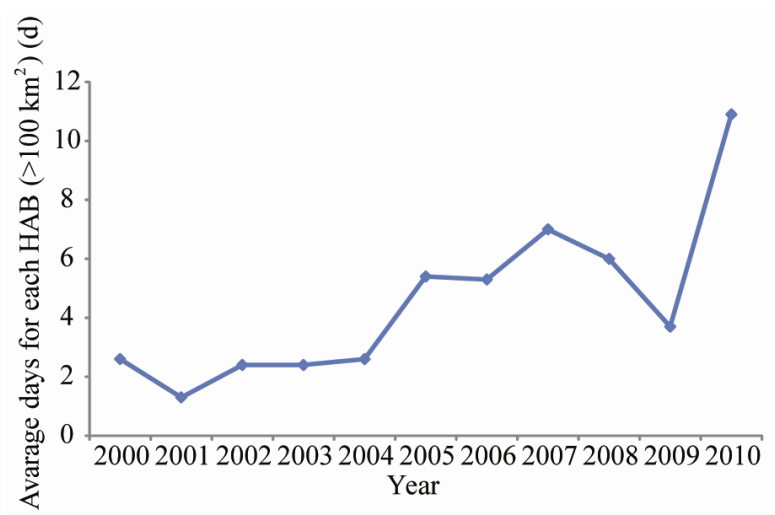

Figure 7. Annually averaged duration of each large-scale HAB $\left(>100 \mathrm{~km}^{2}\right)$ event in the Yangtze Estuary and the adjacent ECS from 2000 to 2010.

quent HABs in the ECS.

\subsection{Contributing Factors for Large-Scale HABs}

Multiple contributing factors can lead to the formation of large-scale HABs in the study area. The severe eutrophi-

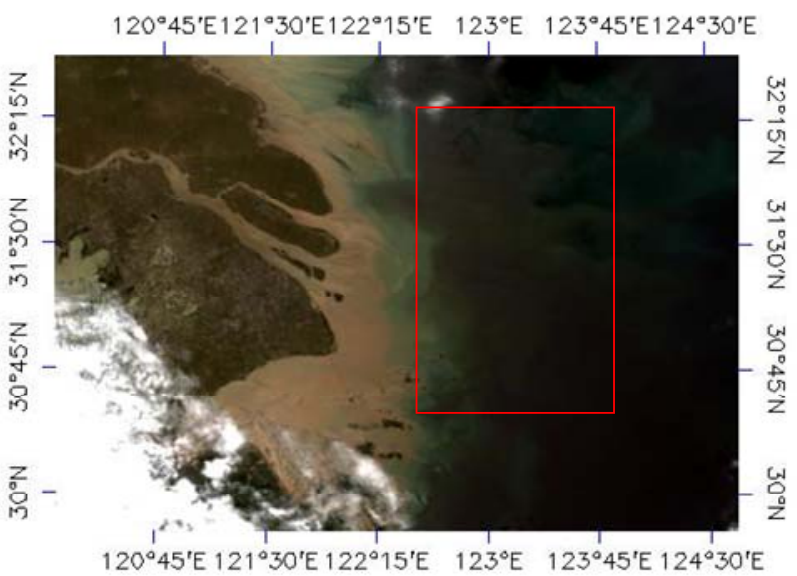

(a)

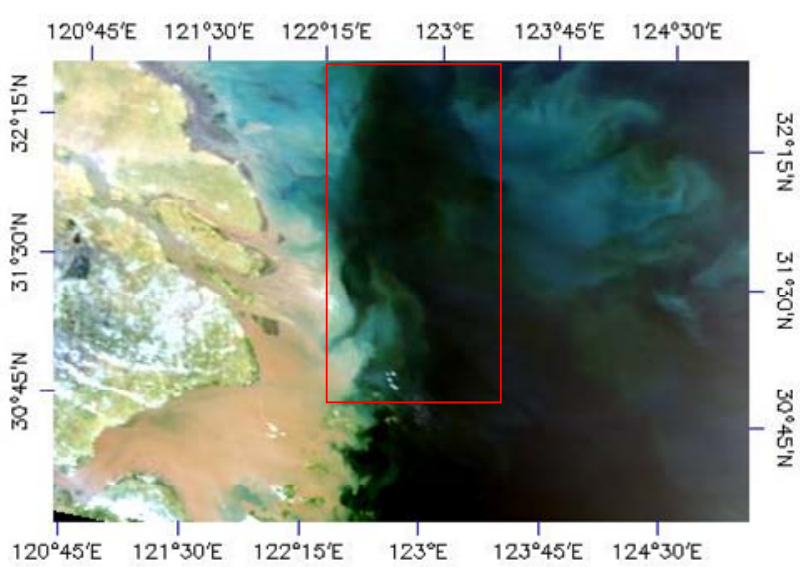

(b)

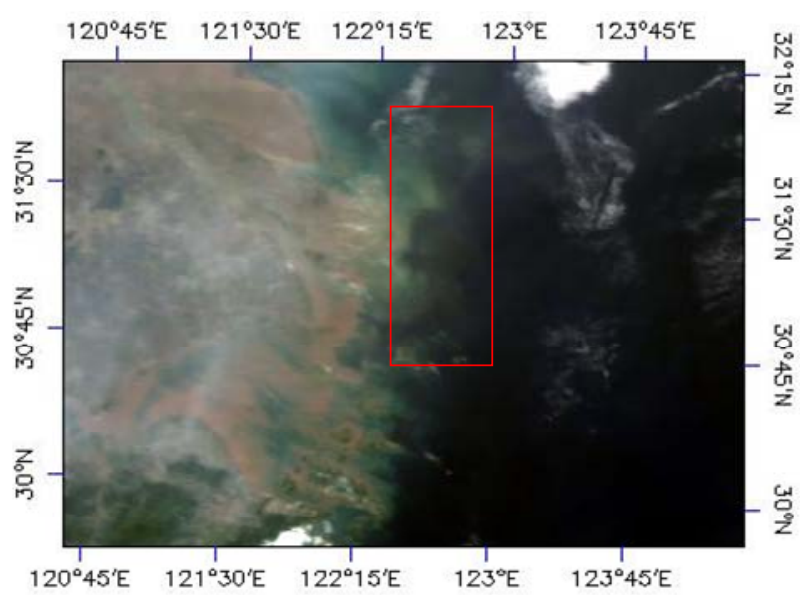

(c)

Figure 8. Water discoloration of HABs in MODIS true color composite images. (a). MODIS true color image on May 25, 2005; (b). MODIS true color image on May 29, 2005; (c). MODIS true color image on June 16, 2005.

cation along with high productivity in the ECS was thought to be the main inducement of frequent HABs by 
influencing the congregation rate of phytoplankton species [18]. An extremely high cell concentration of phytoplankton species resulted from exponential propagation can indicate a corresponding HAB [19]. The cell concentration peak in the ECS normally appears in June to September such as Skeletonema costatum with average abundance of $7.93 \times 104$ cell L $\mathrm{L}^{-1}$ [20]. Increasing amounts of nutrients from the Yangtze River runoff went to the ECS every year, which provided necessary phosphorus and nitrogen concentration to flourish HAB species [21]. Anthropogenic effects such as overuse of fertilizers, in- dustrial sewage and excess fishery in the coastal cities (e.g. Shanghai, Hangzhou and Ningbo) also play an important role in leading to the eutrophication condition $[20,22]$.

Besides, our study area is impacted by complicated oceanographic processes and dynamics involving Taiwan Warm Current $\left(16^{\circ} \mathrm{C}\right.$ to $\left.29.5^{\circ} \mathrm{C}\right)$, the Yangtze Diluted Water $\left(>22^{\circ} \mathrm{C}\right)$, the Yellow Sea Cold Current, the Kuroshio Current and the Zhejiang Coastal Current, which can bring tremendous amounts of nutrients from different sources. Particularly the Yangtze Diluted Water serves as the main nutrient source because of the high suspended sediment deposition in the area of west $122.5^{\circ} \mathrm{E}$. A convergence zone characterized by the temperature and salinity fonts is formed also around $122.5^{\circ} \mathrm{E}$ where the Taiwan Warm Current meets with the nutrient-rich Yangtze River, favorable for the formation of HABs. The northward advection of the Taiwan Warm Current also plays a significant role to transport nutrients from a remote source in Taiwan Strait. Meanwhile, the Zhejiang Coastal Current can bring nutrients up to the HAB region from the subsurface layer in the upwelling zones $[7,8,11,23,24]$.

Thirdly, our study area, on the northwest continental shelf of the ECS, is characterized by special topography and sediment deposition favorable for the HAB occurrences. The west slope of $6 \times 10^{-3}$ in the deep trough has positive effects on the formation of upwelling currents $[25,26]$. The large-scale HABs locate in the high-velocity deposition zone in which nutrients at the bottom sediments can facilitate the implantation of algal cyst hypopus by the resuspending process particularly in summer $[26,27]$. That can explain why summer is the peak period for frequent large-scale HABs [28].

\subsection{Strategies for HABs Monitoring and Management}

For future monitoring and management of large-scale HABs, there are some points that should be taken into consideration. First, it is necessary to establish a synthesized $\mathrm{HAB}$ system in the areas of frequent large-scale HABs by combining multiple data sources including satellite remote sensing, aerial photography, in situ ship- tracking surveys, autonomous moorings, and laboratory analysis into a whole database. Particularly remote sensing techniques are promising to conduct comprehensive HAB research at different spatial and temporal scales. Multiple satellite imagery can be fully utilized to extract water classification and biophysical parameters distribution for monitoring and forecasting HABs. Second, it is of great help to enhance the previous HAB database by investigating the spatial-temporal pattern of historical large-scale HABs caused by different phytoplankton species in a long period. In addition, multiple contributing factors in biochemistry, physical dynamics, geology and meteorology should be comprehensively studied for better understanding the true mechanism the large-scale HABs.

\section{Conclusions}

The results in the present study show that from 2000 to 2010 the Yangtze Estuary, Zhoushan island, Xiangshan bay and Jiushan island are the regions with highest frequency of large-scale HAB. HABs in the ECS reached a peak in terms of total number and total area in 2003 to 2005 and occupied a high percentage of HABs in the four Chinese coastal waters. Number of large-scale HABs (> $1000 \mathrm{~km}^{2}$ ) in the Yangtze Estuary and the adjacent ECS declined after 2005 while that of HABs $\left(>100 \mathrm{~km}^{2}\right)$ declined after 2008. Large-scale HABs occurrences concentrated in summer (May to July) accounted for $78.4 \%$ of the total HABs in the past 11 years. The averaged duration for HABs $\left(>100 \mathrm{~km}^{2}\right)$ increased continually with the shortest time (1.3) days in 2001 and the longest (10.9 days) in 2010. In the study area 17 causative species were found for those large-scale HABs $\left(>100 \mathrm{~km}^{2}\right)$ with Prorocentrum dentutam as the most frequent dominant species, followed by Skeletonema costatum, Karenia mikimotoi, and Chaetoceros curvisetus from 2000 to 2010. Water discoloration found in satellite true color composite imagery was well consistent with distributions of the corresponding HABs in 2005 reported by SOA, falling in the regions of frequent HABs derived from GIS spatial analyst. Multiple factors involving eutrophication, physical dynamics, topography and deposition conditions can explain the formation of such large-scale HABs in the ECS. Three strategies including establishing a synthesized system, improving the previous database and investting multiple contributors were proposed for future HABs monitoring and management.

\section{Acknowledgements}

This research was supported by the program of Key Laboratory of Marine Geology in Tongji University under number MG20080104 and Foundation of Shanghai Science and Technology Committee on Key Projects under number 
09DZ1201000. The authors also would like to acknowledge the reviewers for their comments and suggestions on this manuscript.

\section{REFERENCES}

[1] D. M. Anderson, "Turning Back the Harmful Red Tide,” Nature, Vol. 388, 1997, pp. 513-514. doi:10.1038/41415

[2] J. H. Wang and J. Y. Wu, "Occurrence and Potential Risks of Harmful Algal Blooms in the East China Sea," Science of the Total Environment, Vol. 407, No. 13, 2009, pp. 4012-4021. doi:10.1016/j.scitotenv.2009.02.040

[3] D. M. Anderson, P. M. Glibert and J. M. Burkholder, "Harmful Algal Blooms and Eutrophication: Nutrient Sources, Composition, and Consequences,” Estuaries, Vol. 25, No. 4b, 2002, pp. 704-726. doi:10.1007/BF02804901

[4] D. M. Anderson, "Approaches to Monitoring, Control and Management of Harmful Algal Blooms (HABs)," Ocean and Coastal Management, Vol. 52, No. 7, 2009, pp. 342347. doi:10.1016/j.ocecoaman.2009.04.006

[5] D. M. Anderson, “Toxic Algal Blooms and Red Tides: A Global Perspective,” In: T. Okaichi, D. M. Anderson and T. Nemoto, Eds., Red Tides: Biology Environmental Science and Toxicology, Elsevier, New York, 1989, pp. 1116.

[6] D. L. Tang, D. R. Kester, I-H. Ni, et al., "In Situ and satEllite Observations of a Harmful Algal Bloom and Water Condition at the Pearl River Estuary in Late Autumn 1998," Harmful Algae, Vol. 2, No. 2, 2003, pp. 89-99. doi:10.1016/S1568-9883(03)00021-0

[7] D. L. Tang, B. P. Di, G. F. Wei, et al., "Spatial, Seasonal and Species Variations of Harmful Algal Blooms in the South Yellow Sea and East China Sea,” Hydrobiologia, Vol. 568, No. 1, 2006, pp. 245-253. doi:10.1007/s10750-006-0108-1

[8] L. Shen, H. P. Xu and P. Wu, "Marine Environmental Characteristics of the Yangtze River Estuary and the Adjacent East China Sea during Algal Blooms,” Marine Environmental Science, Vol. 29, 2010, pp. 631-635.

[9] G. F. Wei, D. L. Tang, and S. F. Wang, "Distribution of Chlorophyll and Harmful Algal Blooms (HABs): A Review on Space Based Studies in the Coastal Environments of Chinese Marginal Seas," Advances in Space Research, Vol. 41, No. 1, 2008, pp. 12-19. doi:10.1016/j.asr.2007.01.037

[10] C. S. Chen, J. R. Zhu, R. C. Beardsley, et al., "PhysicalBiological Sources for Dense Algal Blooms near the ChangJiang River," Geophysical Research Letters, Vol. 30, No. 10, 2003, pp. 22-25. doi:10.1029/2002GL016391

[11] J. M. Zhou, Z. L. Shen and R. C. Yu, "Responses of a Coastal Phytoplankton Community to Increased Nutrient Input from the Changjiang (Yangtze) River," Continental Shelf Research, Vol. 28, No. 12, 2008, pp. 1483-1489. doi:10.1016/j.csr.2007.02.009

[12] SOA (the State Oceanic Administration of China), "The China Marine Environmental Quality Bulletin,” 2000-2010a.
http://www.soa.gov.cn/soa/hygb/hjgb/A010901index_1.ht $\mathrm{m}$

[13] SOA (The State Oceanic Administration of China), "The China Marine Disasters Bulletin,” 2000-2010b. http://www.soa.gov.cn/soa/hygb/zhgb/A010902index_1.h tm

[14] SOA (The State Oceanic Administration of China), "The Shanghai Marine Environmental Quality Bulletin,” 20002010c.

http://www.eastsea.gov.cn/Module/more.aspx?categoryid $=70$

[15] SOA (the State Oceanic Administration of China), “Technical Specification of Algal Harmful Blooms,” HY/T0692005, 2005

[16] A. C. Gatrell, T. C. Bailey, P. J. Diggle, et al., "Spatial Points Pattern Analysis and Its Application Geographical Epidemiology," Transactions of the Institute of British Geographers, Vol. 21, No. 1, 1996, pp. 256-274. doi:10.2307/622936

[17] R. P. Stumpf and M. C. Tomlinson, "Remote Sensing of Harmful Algal Blooms,” In: R. L. Miller, C. E. Del Castillo and B. A. McKee, Eds., Remote Sensing of Coastal Aquatic Environments, Springer, AH Dordrecht, 2005, pp. 277-296. doi:10.1007/978-1-4020-3100-7_12

[18] I. V. Telesh, "Plankton of the Baltic Estuarine Ecosystems with Emphasis on Neva Estuary: A Review of Present Knowledge and Research Perspectives,” Marine Pollution Bulletin, Vol. 49, No. 2, 2004, pp. 206-219. doi:10.1016/j.marpolbul.2004.02.009

[19] J. H. Wang, "HAB Alga nearby Yangtze Estuary,” Marine Environmental Science, Vol. 21, 2002, pp. 38-41.

[20] X. Gao and J. Song, "Phytoplankton Distributions and Their Relationship with the Environment in the Changjiang Estuary, China,” Marine Pollution Bulletin, Vol. 50, No. 3, 2005, pp. 327-335. doi:10.1016/j.marpolbul.2004.11.004

[21] J. K. Egge, "Are Diatoms Poor Competitors at Low Phosphate Concentrations?” Journal of Marine Systems, Vol. 16, No. 3-4, 1998, pp. 191-198. doi:10.1016/S0924-7963(97)00113-9

[22] S. F. Ye, H. H. Ji, L. Cao, et al., "Red Tides in the Yangtze River Estuary and Adjacent Sea Areas: Causes and Mitigation," Marine Science, Vol. 28, 2004, pp. 26-32.

[23] Y. L. L. Chen, H. Y. Chen, G. C. Gong, et al., "Phytoplankton Production during a Summer Coastal Upwelling in the East China Sea," Continental Shelf Research, Vol. 24, No. 12, 2004, pp. 1321-1338. doi:10.1016/j.csr.2004.04.002

[24] D. L. Tang, I.-H. Ni, F. E. Müller-Karger, et al., “Analysis of Annual and Spatial Patterns of CZCS-Derived Pigment Concentrations on the Continental Shelf of China," Continental Shelf Research, Vol. 18, 1998, pp. 14931515. doi:10.1016/S0278-4343(98)00039-9

[25] T. Z. Yan, "Primary Classification of Causes for Coastal Upwelling Currents in China,” Marine Bulletin, Vol. 10, 
1991, pp. 1-6.

[26] T. Z. Yan, “Analysis of Causes of Coastal Upwelling Currents in Zhejiang and Qiongdong,” Acta Oceanologica Sinica, Vol. 14, 1992, pp. 12-18.

[27] Z. M. Niu, "Preliminary Study of Deposition Effects of the
Yangtze Estuary Delta,” Marine Geology and Quaternary Geology, Vol. 3, 1983, pp. 1-15.

[28] T. H. Fang, "Phosphorus Speciation and Budget of the East China Sea," Continental Shelf Research, Vol. 24, No. 12, 2004, pp. 1285-1299. doi:10.1016/j.csr.2004.04.003 